\title{
Mild Progressive Osseous Heteroplasia Overlap Syndrome With PTH and TSH Resistance Appearing During Adolescence and Not Early Childhood
}

\section{Kayo Ozaki ( $\square$ adachi_kch@hp.pref.hyogo.jp)}

Hyogo Prefectural Kobe Children's Hospital: Hyogo Kenritsu Kodomo Byoin https://orcid.org/00000002-0938-8967

\section{Akari Mituboshi}

Hyogo Prefectural Kobe Children's Hospital: Hyogo Kenritsu Kodomo Byoin

\section{Masashi Nagai}

Hyogo Prefectural Kobe Children's Hospital: Hyogo Kenritsu Kodomo Byoin

\section{Atushi Nishiyama}

Kakogawa Chuo City Hospital

\section{Gen Nishimura}

Saitama Medical University Hospital: Saitama Ika Daigaku Byoin

\section{Naoya Morisada}

Hyogo Prefectural Kobe Children's Hospital: Hyogo Kenritsu Kodomo Byoin

\section{Kazumoto lijima}

Kobe University Graduate School of Medicine School of Medicine: Kobe Daigaku Daigakuin Igakukei Kenkyuka Igakubu

\section{Research Article}

Keywords: POH overlap syndrome, deep ectopic ossification, sporadic GNAS mutation, PTH/TSH resistance

Posted Date: May 10th, 2021

DOI: https://doi.org/10.21203/rs.3.rs-457399/v1

License: (c) (1) This work is licensed under a Creative Commons Attribution 4.0 International License. Read Full License

Version of Record: A version of this preprint was published at Endocrine on July 13th, 2021. See the published version at https://doi.org/10.1007/s12020-021-02821-y. 


\section{Abstract}

Purpose: Progressive osseous heteroplasia $(\mathrm{POH})$, a genetic disorder, is associated with Albright's hereditary osteodystrophy (AHO), pseudohypoparathyroidism, and primary osteoma cutis and has common features of superficial ossification and GNASinactivating mutations. Disorders due to GNASinactivating mutations are classified as "inactivating parathyroid hormone (PTH)/PTHrP signaling disorder type 2." This study reports a case of mild $\mathrm{POH}$ overlap syndrome to improve understanding of genotype-phenotype correlations.

Methods: A 13-year-and-6-month-old Japanese boy was referred to our hospital with a chief complaint of the lower limb length difference. He underwent clinical, biochemical, radiological, and genetic studies.

Results: He showed sporadic GNAS mutation, deep ectopic ossification, small for gestational age (SGA), congenital tooth defect, and lack of AHO features; he met the diagnostic criteria for $\mathrm{POH}$, and mild PTH and TSH resistance was detected. He had constant hyperphosphatasemia and hypocalciuria. At the age of 10 years, he occasionally experienced high iPTH levels. The pituitary stimulation test showed a normal response of all hormones at 3 years of age, but TSH response was decreased (previously 0.770, peak value $4.144 \mu \mathrm{lU} / \mathrm{mL}$ ) in the TRH loading test at age 13 years and 6 months. DNA analysis showed a heterozygous p.D189MfsTer14 mutation of GNAS. The parents did not carry this mutation.

Conclusion: We report a rare case of $\mathrm{POH}$ overlap syndrome with PTH/TSH resistance that appeared in adolescence rather than early childhood. Cases diagnosed with $\mathrm{POH}$ in early childhood also require reassessment during adolescence. Further studies of the GNAS heterozygous mutation p.D189MfsTer14 may reveal factors involved in $\mathrm{POH}$ overlap syndrome.

\section{Introduction}

Progressive osseous heteroplasia $(\mathrm{POH})$ is an extremely rare hereditary disease characterized by progressive ectopic ossification [1]. $\mathrm{POH}$ is a genetic disorder associated with Albright's hereditary osteodystrophy (AHO), pseudohypoparathyroidism (PHP), and primary osteoma cutis and has common features of superficial ossification and GNASinactivating mutations. Patients with POH usually do not have parathyroid hormone (PTH) resistance; however, there have been reports of $\mathrm{POH}$ overlap syndrome where $\mathrm{AHO}$ or PHP features are present besides $\mathrm{POH}$ features [2]. Diagnosis of $\mathrm{POH}$ overlap syndrome is made on the basis of only clinical symptoms. There are currently only a few detailed reports of $\mathrm{POH}$ overlap syndrome, and thus, the condition is poorly understood. We report a rare case of $\mathrm{POH}$ overlap syndrome with PTH/TSH resistance that appeared in adolescence but not during early childhood.

\section{Materials And Methods}

\section{Subject}


A 13-year-and-6-month-old Japanese boy was referred to our hospital with a chief complaint of the lower limb length difference. He was born at 32 weeks and 4 days gestation and was SGA; weight of $928 \mathrm{~g}$ and height of $36.0 \mathrm{~cm}$ ). His medical history showed a congenital tooth defect. He has been receiving growth hormone therapy for SGA short stature since the age of 3 years and 2 months.

When he entered junior high school, he noticed a right > left difference in leg length (Fig. 1a). An abnormal shadow was discovered on the foot during the presurgical inspection of orthopedic surgery for lower limb length difference, which was suspected to be progressive ossifying fibrodysplasia. He was referred to the Departments of Clinical Genetics and Metabolic Endocrinology.

\section{Biochemical and imaging analyses}

Blood and urine tests were conducted regularly from age 7 years and 2 months to 13 years and 2 months at his original hospital. He underwent biochemical and radiological studies, including ultrasonography, of the abdomen.

\section{Genetic analyses}

We conducted genetic analysis after obtaining written informed consent from the patient and parents. All procedures were reviewed and approved by the institutional review board of Kobe University School of Medicine and were conducted according to the ethical standards of the 1964 Declaration of Helsinki. Genomic DNA was extracted from peripheral blood mononuclear cells using the QuickGene whole blood kit (Kurabo, Osaka, Japan). We utilized an Illumina ${ }^{\circledR}$ TruSight $^{\text {TM }}$ One sequencing panel on a MiSeq platform following the manufacturer's instructions (Illumina San Diego, CA, USA). Mutations were confirmed via standard Sanger sequencing.

\section{Results}

\section{Subject}

The patient was $157.3 \mathrm{~cm}$ tall $(-0.27 \mathrm{SD})$ and weighed $43.4 \mathrm{~kg}(-0.66 \mathrm{SD})$. The average height and weight of similarly aged Japanese boys (2000) are $160.0 \pm 7.7 \mathrm{~cm}$ and $50.4 \pm 10.5 \mathrm{~kg}$, respectively. $\mathrm{He}$ has never been overweight (Fig. 1b). Signs of puberty were Tanner stage 3 for testicles and Tanner stage 3 for pubic hair. He had no signs of AHO, such as round face, obesity, brachydactyly, metacarpal/metatarsal shortening, or developmental delay (Fig. 1c). No subcutaneous osteoma was found on his skin. Ectopic ossification appeared on the outside of his right hand at age 5 years and on the sole of his left foot at age 9 years.

\section{Biochemical and imaging analyses}

He had constant hyperphosphatasemia and hypocalciuria. Hypocalciuria assessment showed a serum calcium level of $9.6 \mathrm{mg} / \mathrm{dL}$ and FECa was low $(0.00 \%$; mean FECa in the presence of normocalcemia is $2 \%$ [range $1.5-3.0 \%]$ ). At the age of 10 years, he occasionally had high iPTH levels. His renal function 
was impaired (CKD stage 2). He had no albuminuria or proteinuria, and his estimated glomerular filtration rate was $61.1-80.1 \mathrm{~mL} / \mathrm{min} / 1.73 \mathrm{~m}^{2}$. Imaging findings revealed his right kidney measured $10.2 \times 5.1 \mathrm{~cm}$ with multiple renal calcifications.

His urinary cyclic adenosine monophosphate (cAMP) response to PTH given intravenously was normal.

The pituitary stimulation test showed that all hormones responded normally at age 3 years; however, TSH response was decreased (previously 0.770 , peak value $4.144 \mu \mathrm{lU} / \mathrm{mL}$ ) in the TRH loading test at age 13 years and 6 months. Concurrent PRL reactions were normal, which demonstrated that TRH loading was not an issue. GH, LH, and FSH responded normally (Fig. 2).

At the age of 13 years, radiographs showed shortening of the left femoral neck and lateral ectopic ossification of the left floor and right hand (Fig. 1d-f).

\section{Genetic analyses}

DNA analysis showed a heterozygous p.D189MfsTer14 mutation of the GNAS gene. The parents did not carry this mutation (Fig. 3).

\section{Discussion}

We present a case of POH overlap syndrome (POH/PHP1a/1c) who showed a sporadic GNAS mutation, deep ectopic ossification, SGA, congenital tooth defect, and lack of AHO features. This patient met the diagnostic criteria of $\mathrm{POH}$, and mild PTH and TSH resistance was detected.

PHP, the first known post-receptor hormone resistance, is caused by a partial deficiency of the a subunit of the stimulatory $G$ protein (Gsa), which is a key component of the PTH/PTHrP signaling pathway. Since its first description, besides the molecular basis of PHP, various studies have revealed the existence of numerous subtypes and differential diagnoses associated with genetic alterations of the PTH/PTHrP pathway. The clinical and molecular overlap of PHP subtypes and other related disorders presents challenges for both differential diagnosis and genetic counseling [3].

In 2016, the EuroPHP network developed a new classification that encompasses all disorders involving impairments in PTH and/or PTHrP cAMP-mediated pathways [4]. Elli and Mantovani reviewed the major and minor features characterizing inactivating PHP or PTH/PTHrP signaling disorders (iPPSDs) as a group and the specificities and overlap associated with the most frequent subtypes [3]. Their descriptions on $\mathrm{POH}$ are in line with our findings

Because there are only a few detailed reports of $\mathrm{POH}$ overlap syndrome, there remain numerous unclear points regarding additional $\mathrm{AHO}$ or $\mathrm{PHP}$ features that are present alongside $\mathrm{POH}$ features. The diagnosis of $\mathrm{POH}$ overlap syndrome is made on the basis of only clinical symptoms [2]. There are further uncertainties about POH. For example, our patient was first diagnosed at age 13 years and 6 months despite $\mathrm{POH}$ usually being diagnosed within the first year of life [5]. Moreover, although Shore et al. 
demonstrated that most cases of POH are caused by paternally inherited inactivating mutations of GNAS [6], our patient showed both $\mathrm{POH}$ and PHP la, which are apparently due to a de novo mutations of GNAS.

Recently, Pereda et al. proposed new criteria and classifications of iPPSDs. Moreover, current work is focused on improving classifications of PHP and related disorders [7]. POH is diagnosed on the basis of three major criteria: superficial heterotopic ossification $(\mathrm{HO})$ that progresses to deep connective tissue, no more than two AHO features, and no PTH resistance [8]. Progressive extension of HO into deep connective tissue, congenital tooth defects, and shortening of the left femoral neck are considered AHO symptoms. However, PTH tolerance is a characteristic symptom of PHP1A [1].

It has been recently reported that severe $\mathrm{POH}$ without PHP1A/1C features is caused by paternally inherited inactivating mutations of GNAS, whereas mild cases of POH with AHO/PHP1A features are caused by maternal inherited inactivating mutations of GNAS [9]. There have been three reports of a mild case of POH/PHP1A [10-12], which showed that hormone resistance was not observed the time of initial POH identification, and hormone tolerance appeared months or years later (Table 1).

Table 1

Clinical and molecular characteristics of cases reported in the literature harboring mild $\mathrm{POH}$

\begin{tabular}{|llllll|}
\hline Authors & GNAS mutation & $\begin{array}{l}\text { Familial } \\
\text { transmission/mutated } \\
\text { allele }\end{array}$ & $\begin{array}{l}\text { Age of onset } \\
\text { of } \\
\text { Heterotopic } \\
\text { ossification }\end{array}$ & $\begin{array}{l}\text { Age of } \\
\text { onset of } \\
\text { PTH } \\
\text { resistance }\end{array}$ & $\begin{array}{l}\text { Age of } \\
\text { onset of } \\
\text { TSH } \\
\text { resistance }\end{array}$ \\
\hline $\begin{array}{l}\text { Elli, F.M., } \\
\text { et al. }\end{array}$ & c.565_568delGACT & denovo/maternal & 6 months & 3 years & 3 years \\
\hline $\begin{array}{l}\text { Lebrun, } \\
\text { M., et al. }\end{array}$ & c.565_568delGACT & denovo/maternal & 6 months & 1 year & 1 year \\
$\begin{array}{l}\text { Gelfand, } \\
\begin{array}{l}\text { L.M., et } \\
\text { al. }\end{array}\end{array}$ & c.546delC & de novo/unknown & 1 month & $\begin{array}{l}16 \\
\text { months }\end{array}$ & 4 months \\
\hline
\end{tabular}

The heterozygous mutation p.D189MfsTer14 of GNAS identified in our case is not only a POH hereditary mutation but also a mutation hotspot of AHO/PHP1A, so it may exhibit a wide range of phenotypes [8, 10]. Genetic background, modified genes, epigenetic modifications, and environmental factors are believed to be factors that contribute to $\mathrm{POH}$ overlap syndrome [9]. Further studies of the GNAS heterozygous mutation p.D189MfsTer14 may reveal the factors that are involved in $\mathrm{POH}$ overlap syndrome.

It remains unclear whether $\mathrm{POH}$ overlap syndrome is associated with progressive bone age, the appearance of intellectual impairment, or gonadal dysfunction [1]. In our case, there were no abnormalities in bone age progression, intelligence, or gonadal function. Given the rarity of $\mathrm{POH} / \mathrm{PHP} 1 \mathrm{C} / 1 \mathrm{C}$, further cases will need to be investigated to elucidate these uncertainties. 
In summary, we present a rare case of $\mathrm{POH}$ overlap syndrome (POH/PHP1A/1C), which was diagnosed only by clinical symptoms. $\mathrm{POH}$ is usually diagnosed by the age of 1 year; however, our patient was first diagnosed at age 13 years and 6 months because the bone lesions were much milder than previously reported. Genetic background, modified genes, epigenetic modifications, and environmental factors are believed to be factors that contribute to POH overlap syndrome [9]. Further studies of POH cases will enable the identification of factors associated with $\mathrm{POH}$ overlap syndrome. Moreover, additional studies of the GNAS heterozygous mutation p.D189MfsTer14 will provide a better understanding of the factors involved in $\mathrm{POH}$ overlap syndrome.

\section{Declarations}

\section{Acknowledgments}

None

\section{Funding}

No funding was received for conducting this study.

\section{Conflict of interest}

None of the authors have any potential conflicts of interest associated with this research.

\section{Availability of data and material Code availability}

Not applicable

\section{Author contributions}

Conceptualization and Writing - original draft preparation: Kayo Ozaki;

Formal analysis: Naoya Morisada and Kazumoto lijima;

Investigation: Gen Nishimura, Akari Mituboshi, and Masashi Nagai;

Resources: Atushi Nishiyama

\section{Ethical approval}

All procedures performed in studies involving human participants were in accordance with the ethical standards of the institutional and/or national research committee (Hyogo Prefectural Kobe Children's Hospital committee + reference number: R3-1) and with the 1964 Helsinki declaration and its later amendments or comparable ethical standards.

\section{Informed consent}


Written informed consent was obtained from the patient and his parents for publication of this case report and any accompanying images.

\section{References}

1. Mantovani, G., Bastepe, M., Monk, D., De Sanctis, L., Thiele, S., Usardi, A, Ahmed, S.F., Bufo, R., Choplin, T., De Filippo, G., Devernois. G.: Diagnosis and management of pseudohypoparathyroidism and related disorders: First international Consensus Statement. Nat. Rev. Endocrinol. 14, 476-500 (2018)

2. Adegbite, N.S., Xu, M., Kaplan, F.S., Shore, E.M., Pignolo, R.J.: Diagnostic and mutational spectrum of progressive osseous heteroplasia $(\mathrm{POH})$ and other forms of GNAS-based heterotopic ossification. Am. J. Med. Genet. A. 146A, 1788-1796 (2008)

3. Elli, F.M. Mantovani, G.: Pseudohypoparathyroidism, acrodysostosis, progressive osseous heteroplasia: Different names for the same spectrum of diseases? Endocrine (2020). https://doi.og/10.1007/s12020-020-02533-9

4. Thiele, S. Mantovani, G., Barlier, A., Boldrin, V., Bordogna, P., De Sanctis, L, Elli, F.M., Freson, K., Garin, I., Grybek, V., Hanna, P.: From pseudohypoparathyroidism to inactivating PTH/PTHrP signalling disorder (iPPSD), a novel classification proposed by the EuroPHP network. Eur. J. Endocrinol. 175, P1-P17 (2016)

5. Mantovani, G., Spada, A., Elli, F.M.: Pseudohypoparathyroidism and Gsa-cAMP-linked disorders: current view and open issues. Nat. Rev. Endocrinol. 12, 347-356 (2016)

6. Shore, E.M., Ahn, J., De Beur, S.J., Li, M., Xu, M., Gardner, R.M., Zasloff, M.A., Whyte, M.P., Levine, M.A., Kaplan, F.S.: Paternally inherited inactivating mutations of the GNAS1 gene in progressive osseous heteroplasia. N. Engl. J. Med. 346, 99-106 (2002)

7. Pereda, A., Elli, F.M., Thiele, S., de Sanctis, L., Rothenbuhler, A., Hanna, P, Francou, B., Ertl, D.A., de Nanclares, G.P., Linglart, A., Mantovani, G.: Inactivating PTH/PTHrP signaling disorders (iPPSDs): Evaluation of the new classification in a multicenter large series of 544 molecularly characterized patients. Eur. J. Endocrinol. 184, 311-320 (2021)

8. Pignolo, R.J., Ramaswamy, G., Fong, J.T., Shore, E.M. Kaplan, F.S.: Progressive osseous heteroplasia: Diagnosis, treatment, and prognosis. Appl. Clin. Genet. 8, 37-48 (2015)

9. Bastepe, M.: GNAS mutations and heterotopic ossification. Bone. 109, 80-85 (2018)

10. Lebrun, M., Richard, N., Abeguilé, G., David, A., Dieux, A.C., Journel, H., Lacombe, D., Pinto, G., Odent, S., Salles, J.P., Taieb, A.: Progressive osseous heteroplasia: a model for the imprinting effects of GNAS inactivating mutations in humans. J. Clin. Endocrinol. Metab. 95, 3028-3038 (2010)

11. Elli, F.M., Barbieri, A.M., Bordogna, P., Ferrari, P., Bufo, R., Ferrante, E, Giardino, E., Beck-Peccoz, P., Spada, A., Mantovani, G.: Screening for GNAS genetic and epigenetic alterations in progressive osseous heteroplasia: First Italian series. Bone. 56, 276-280 (2013) 
12. Gelfand, I.M., Hub, R.S., Shore, E.M., Kaplan, F.S. DiMeglio, L.A.: Progressive osseous heteroplasia-like heterotopic ossification in a male infant with pseudohypoparathyroidism type la: A case report. Bone. 40, 1425-1428 (2007)

\section{Figures}

a

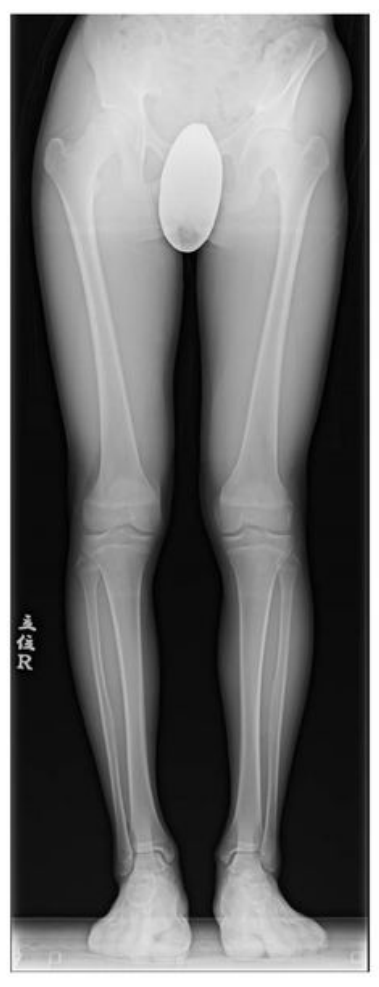

b

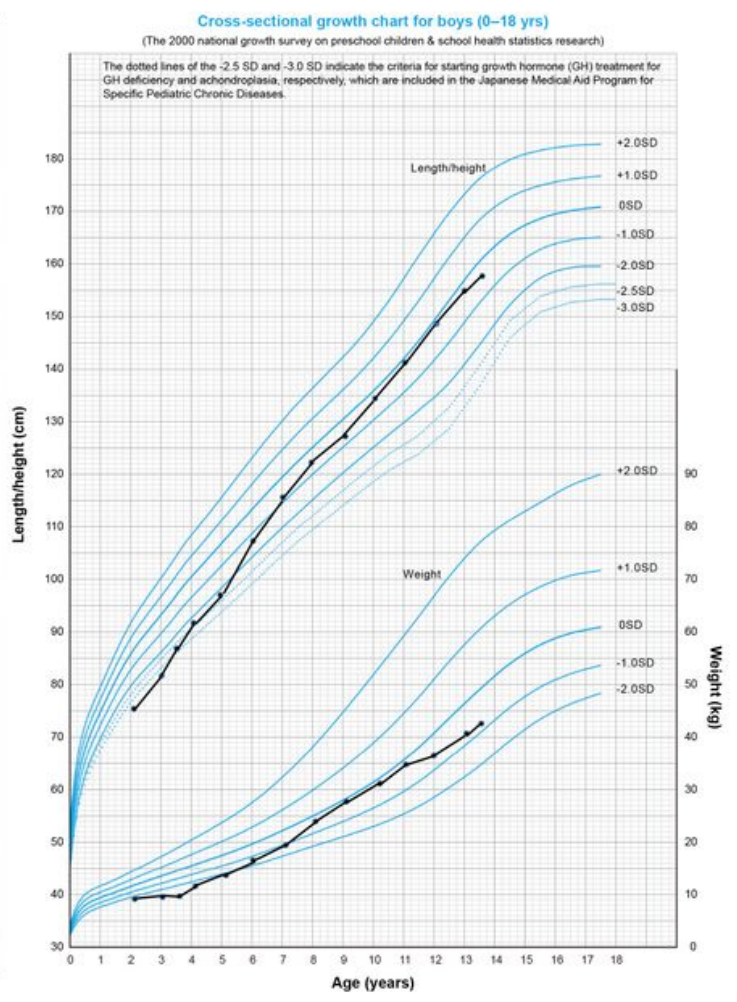

e

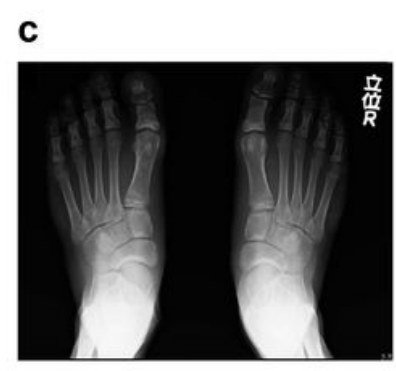

d

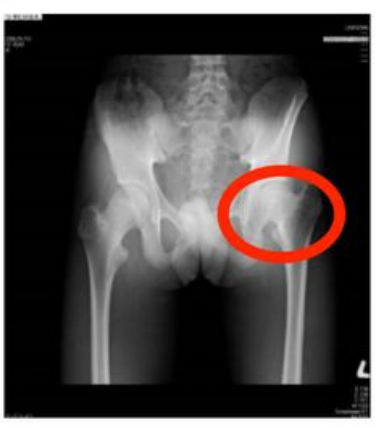

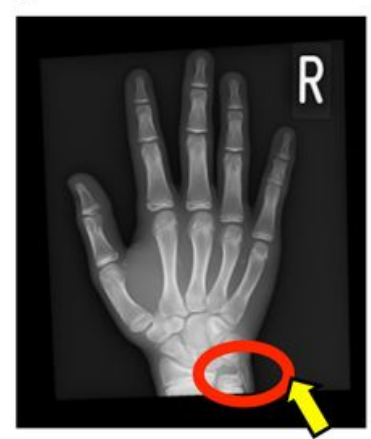

f

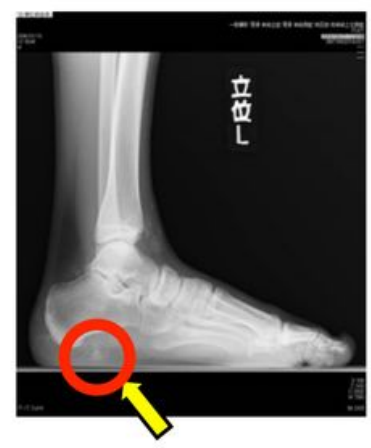

Figure 1

a. Growth charts for height and weight of Japanese boys. The patient has been receiving growth hormone therapy for SGA short stature since age 3 years and 2 months. He has never been overweight. b-f. X-ray of bones. b. Lower limb length difference. c. No brachydactyly on either foot. D. Shortening of the left femoral neck. $e^{-f}$. Ectopic ossification of the right hand and left foot

Insulin

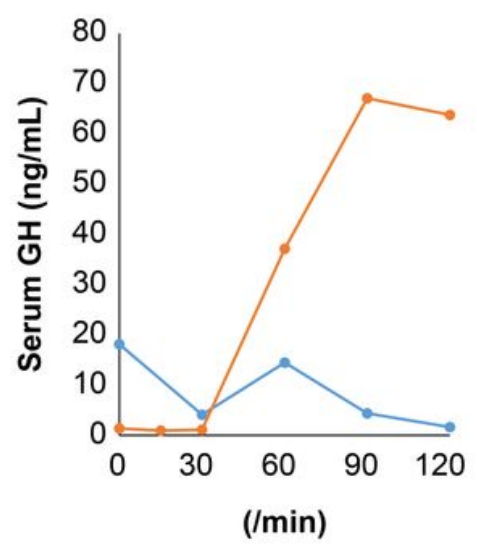

TRH

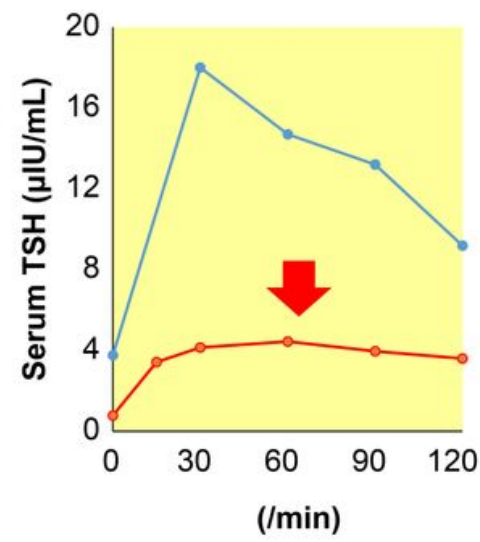

TRH

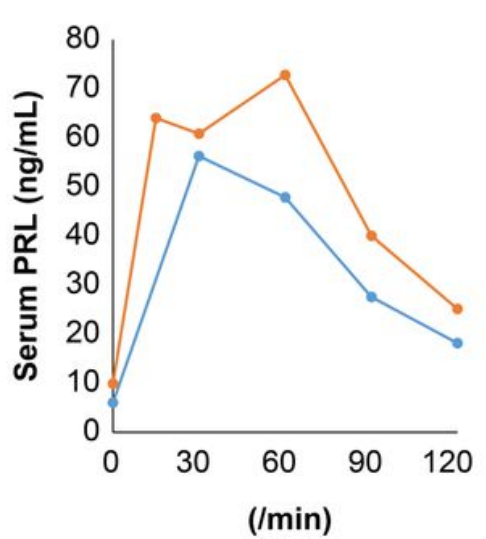

LHRH

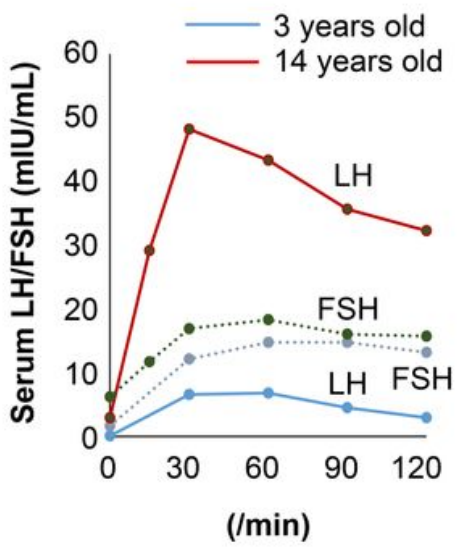


Figure 2

The pituitary stimulation test showed a normal response of all hormones at 3 years of age, but TSH response decreased (previously 0.770 , peak value $4.144 \mu \mathrm{IU} / \mathrm{mL}$ ) in the TRH loading test at 13 years and 6 months (red arrow pointing downward). Concurrent PRL reactions were normal, which demonstrated that TRH loading was not an issue. GH, LH, and FSH responded normally.

\section{GNAS NM_000516.5: c.565_568delGACT, p.Asp189MetfsTer14}
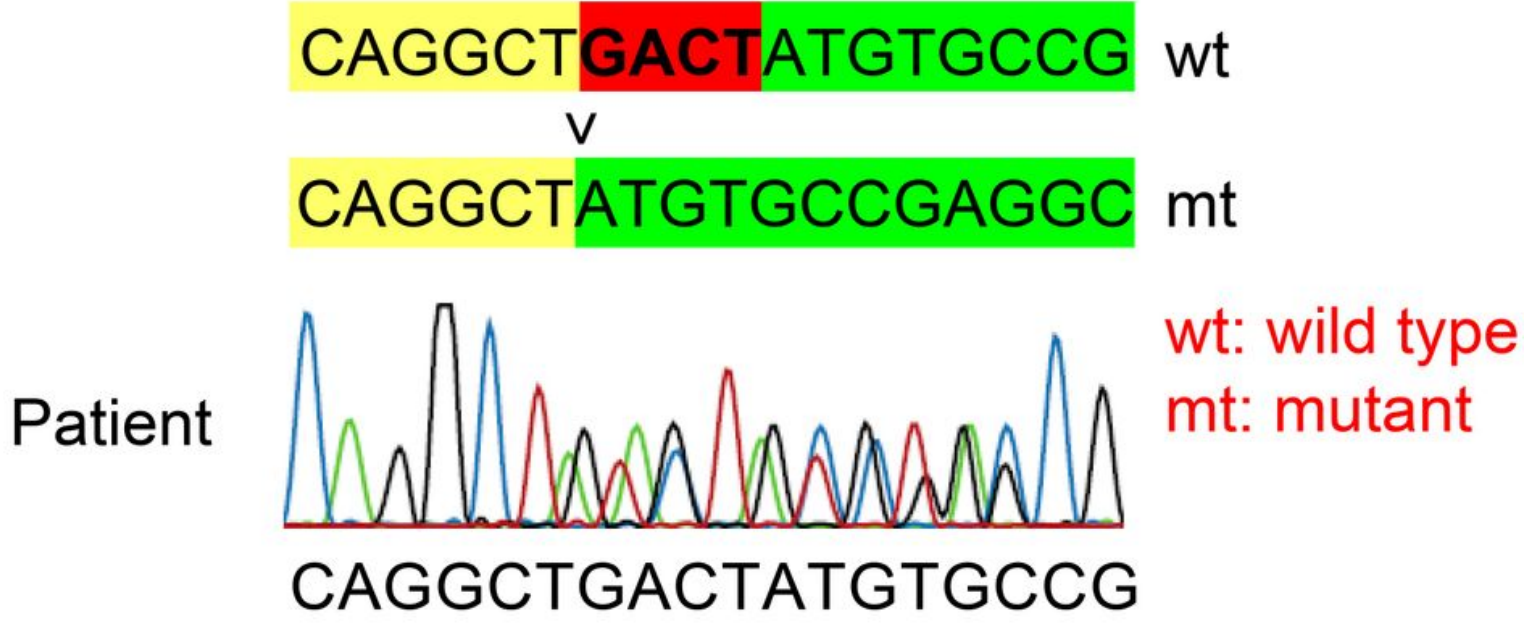

Father

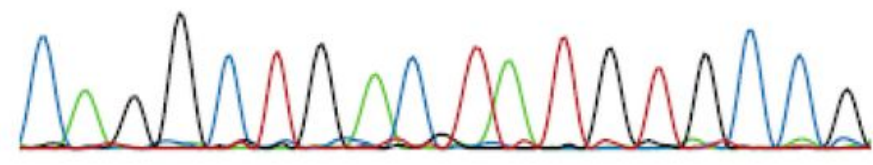

\section{CAGGCTGACTATGTGCCG}

Mother

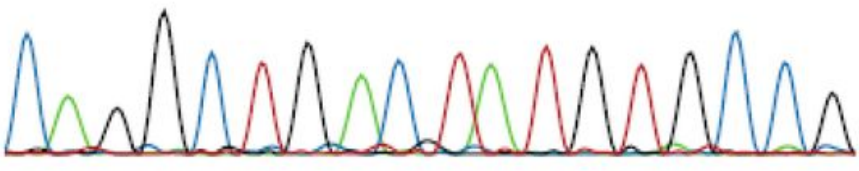

\section{CAGGCTGACTATGTGCCG}

Control

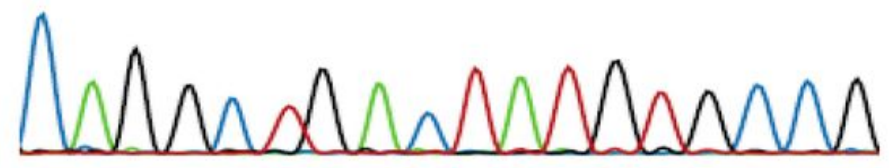

Figure 3

DNA analysis showed a heterozygous p.D189MfsTer14 mutation of the GNAS gene. The parents did not carry this mutation. 